\title{
Opposing Actions of Endothelin-1 on Glutamatergic Transmission onto Vasopressin and Oxytocin Neurons in the Supraoptic Nucleus
}

\author{
Aleksander R. Zampronio, ${ }^{1,2 \star}$ J. Brent Kuzmiski, ${ }^{1 \star}$ Clare M. Florence, ${ }^{3}$ Sean J. Mulligan, ${ }^{3}$ and Quentin J. Pittman ${ }^{1}$ \\ ${ }^{1}$ Hotchkiss Brain Institute and Department of Physiology and Pharmacology, University of Calgary, Calgary, Alberta T2N 4N1, Canada, ${ }^{2}$ Department of \\ Pharmacology, Federal University of Paraná, Curitiba, Brazil 81530 -900, and '²Department of Physiology, University of Saskatchewan, Saskatoon, \\ Saskatchewan S7N 3R2, Canada
}

\begin{abstract}
Endothelin (ET-1) given centrally has many reported actions on hormonal and autonomic outputs from the CNS. However, it is unclear whether these effects are due to local ischemia via its vasoconstrictor properties or to a direct neuromodulatory action. ET-1 stimulates the release of oxytocin (OT) and vasopressin (VP) from supraoptic magnocellular (MNCs) neurons in vivo; therefore, we asked whether ET-1 modulates the excitatory inputs onto MNCs that are critical in sculpting the activity of these neurons. To investigate whether ET-1 modulates excitatory synaptic transmission, we obtained whole-cell recordings and analyzed quantal glutamate release onto MNCs in the supraoptic nucleus (SON). Neurons identified as VP-containing neurosecretory cells displayed a decrease in quantal frequency in response to ET-1 (10-100 pM). This decrease was mediated by $\mathrm{ET}_{\mathrm{A}}$ receptor activation and production of a retrograde messenger that targets presynaptic cannabinoid-1 receptors. In contrast, neurons identified as 0T-containing MNCs displayed a transient increase in quantal glutamate release in response to ET-1 application via $\mathrm{ET}_{\mathrm{B}}$ receptor activation. Application of TTX to block action potentialdependent glutamate release inhibited the excitatory action of ET-1 in OT neurons. There were no changes in quantal amplitude in either MNC type, suggesting that the effects of ET-1 were via presynaptic mechanisms. A gliotransmitter does not appear to be involved as ET-1 failed to elevate astrocytic calcium in the SON. Our results demonstrate that ET-1 differentially modulates glutamate release onto VPversus OT-containing MNCs, thus implicating it in the selective regulation of neuroendocrine output from the SON.
\end{abstract}

\section{Introduction}

Appropriate secretion of hormones from the hypothalamoneurohypophyseal system is essential for maintenance of physiological homeostasis. The neurohormones oxytocin (OT) and vasopressin (VP) are synthesized in the magnocellular neurosecretory cells (MNCs) of the supraoptic nucleus (SON) and paraventricular nucleus of the hypothalamus and released into the bloodstream in the posterior pituitary. Since secretion of these hormones depends on the activity of MNCs and this is tightly coupled to the efficacy of excitatory synapses (Nissen et al., 1995; Moos et al., 1997; Jourdain et al., 1998; Shibuya et al., 2000; Hrabovszky and Liposits, 2008), modulation of glutamatergic neurotransmission is an important mechanism for adjusting neuroendocrine output.

In the hypothalamus, glutamatergic synapses are modulated by numerous neuropeptides. The endothelins (ETs) constitute a

Received Sept. 28, 2010; revised 0ct. 18, 2010; accepted 0ct. 21, 2010.

The study was supported by grants to Q.J.P. and S.J.M. from the Canadian Institutes of Health Research, and to A.R.Z. from the Brazilian National Research Council. Q.J.P. is an Alberta Heritage Foundation for Medical Research Medical Scientist, and A.R.Z. is the recipient of the International Brain Research Organization postdoctoral scholarship. We thank Dr. J. S. Bains for critical comments on the manuscript.

*A.R.Z. and J.B.K. contributed equally to this work.

Correspondence should be addressed to Dr. J. Brent Kuzmiski, Hotchkiss Brain Institute Professor, Department of Physiology \& Biophysics, Faculty of Medicine, University of Calgary, 3330 Hospital Drive NW, Calgary, AB T2N 4N1, Canada.E-mail: jbkuzmis@hotmail.com.

DOI:10.1523/JNEUROSCI.5079-10.2010

Copyright $\odot 2010$ the authors $\quad 0270-6474 / 10 / 3016855-09 \$ 15.00 / 0$ family of peptides (ET-1, ET-2, and ET-3) that act as potent vasoconstrictors (Yanagisawa et al., 1988; Davenport, 2002) and neuromodulators (Zimmermann and Seifert, 1998). The presence of ET-1 and ET-3 has been reported in the hypothalamus (MacCumber et al., 1989; Yoshizawa et al., 1990) including in dendrites of MNCs and axon terminals making synapses with MNCs (Mukherjee and Loesch, 2002). Moreover, ET-1 is colocalized with neurohypophysial hormones in both VPergic and OTergic axons (Nakamura et al., 1993), suggesting that it may be coreleased with VP and OT. The endothelin receptor $\mathrm{ET}_{\mathrm{A}}$ is localized in the SON (Koseki et al., 1989), while $\mathrm{ET}_{\mathrm{B}}$ receptors are distributed in the hypothalamus, most prominently in the organum vasculosum of the lamina terminalis and median eminence (Yamamoto and Uemura, 1998). Studies examining the link between endothelin and neuroendocrine output have revealed that ET-1 induces VP secretion both in vitro (Shichiri et al., 1989; Ritz et al., 1992; Rossi and Chen, 2002, 2006; Rossi, 2004) and in vivo (Rossi et al., 1997a,b, 2008), while intracerebroventricular administration of endothelin stimulates the release of OT (Samson et al., 1991). Furthermore, ET-1 activates both OT and VP MNCs through an action at the subfornical organ (Wall and Ferguson, 1992).

Although the above findings suggest that ET-1 may play a neuromodulatory role in the hypothalamus, the absence of a direct demonstration on synaptic efficacy has led to speculation that the effects of ET-1 on neurohormone release are due to its 
neurovascular actions (Dashwood and Loesch, 2010), resulting in depolarization subsequent to local ischemia (Pittman and Mulligan, 2008). In this regard, other neuropeptides released into the SON have been demonstrated to cause local ischemia (Alonso et al., 2008). It is important to differentiate among these possible actions to interpret the in vivo literature concerning ET-1 effects on MNC output. Therefore, because of a notable lack of mechanistic data concerning ET-1 action in the SON, we used whole-cell recordings from MNCs to test the hypothesis that ET-1 modulates glutamatergic synaptic transmission, independent of its potent vasoconstrictor activity. Here, we show that ET-1 causes a long-lasting decrease in the frequency of quantal events onto VP neurons, while transiently enhancing quantal glutamate release onto OT neurons. Thus, ET-1 may differentially control the output of these two peptides.

\section{Materials and Methods}

Brain slice preparation. All experiments were performed according to protocols approved by the University of Calgary Animal Care Committee in accordance with the guidelines established by the Canadian Council on Animal Care. Hypothalamic slices were prepared from male Sprague Dawley rats (150-200 g) and heterozygous transgenic VP-enhanced green fluorescent protein (VP-eGFP) Wistar rats (Ueta et al., 2005). Animals were anesthetized with halothane, decapitated, and the brains rapidly removed into ice-cold $\left(0-2^{\circ} \mathrm{C}\right)$ slicing solution containing the following (in $\mathrm{mM}$ ): 87 $\mathrm{NaCl}, 2.5 \mathrm{KCl}, 1.25 \mathrm{NaH}_{2} \mathrm{PO}_{4}, 7 \mathrm{MgCl}_{2}, 0.5$ $\mathrm{CaCl}_{2}, 25 \mathrm{NaHCO}_{3}, 25$ glucose, and 75 sucrose (saturated with $95 \% \mathrm{O}_{2}-5 \% \mathrm{CO}_{2}$ ). The brain was blocked, mounted on a vibrating slicer (VT1000S, Leica), and 250- $\mu$ m-thick coronal slices containing the $\mathrm{SON}$ were obtained. Slices were incubated in a submerged chamber of artificial CSF (ACSF) at $32^{\circ} \mathrm{C}$ for $45 \mathrm{~min}$ and then maintained at room temperature for a minimum 45 min before recording. The ACSF contained the following (in $\mathrm{mm}$ ): $126 \mathrm{NaCl}, 2.5$ $\mathrm{KCl}, 1.2 \mathrm{NaH}_{2} \mathrm{PO}_{4}, 1.2 \mathrm{MgCl}_{2}, 2.4 \mathrm{CaCl}_{2}, 18$ $\mathrm{NaHCO}_{3}$, and 11 glucose saturated with $95 \%$ $\mathrm{O}_{2}-5 \% \mathrm{CO}_{2}$. Horizontal hippocampal slices were also prepared in the same manner.

Electrophysiological recordings. Whole-cell patch-clamp recordings were obtained from MNCs in the SON visually identified with an upright microscope (Axioskop2 FS, Zeiss) fitted with infrared differential interference contrast optics. All recordings were obtained at $32-34^{\circ} \mathrm{C}$ using borosilicate glass microelectrodes (tip resistance of 3-5 $\mathrm{M} \Omega$ ) filled with an intracellular solution containing the following (in mM): $108 \mathrm{~K}$-gluconate, $8 \mathrm{Na}$-gluconate, $8 \mathrm{KCl}, 2 \mathrm{MgCl}_{2}, 1$ EGTA, 10 HEPES, 4 K-ATP, and 0.35 Na-GTP, pH 7.2. The identity of MNCs was confirmed by their prominent delay to onset of action potential generation in response to positive current injection (Tasker and Dudek, 1991). OT and VP neurons were distinguished based on the presence or absence of sustained outward rectification and an inward

A
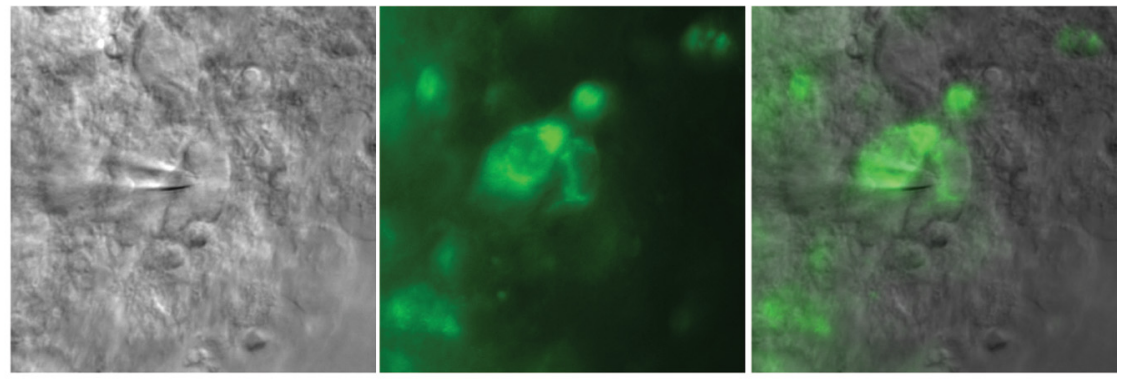

$\mathrm{B}$

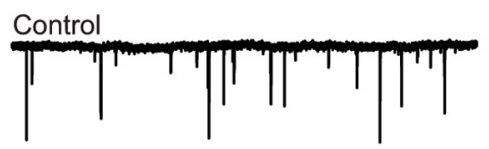

ET-1 100 pM

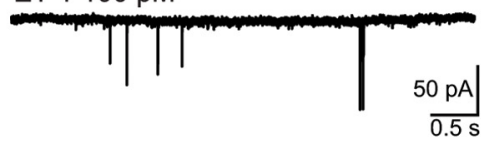

$\mathrm{F}$

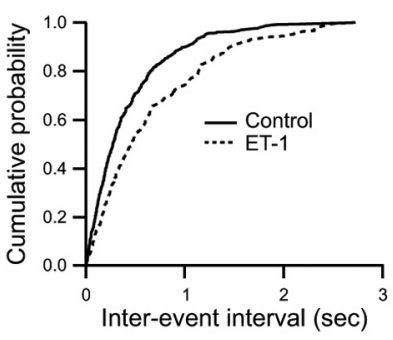

G

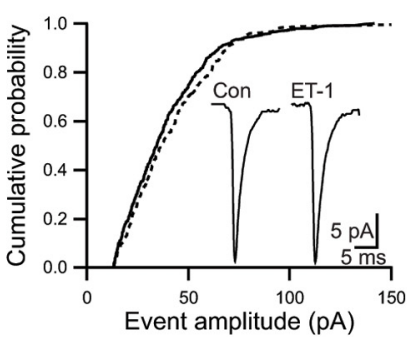

$\mathrm{E}$

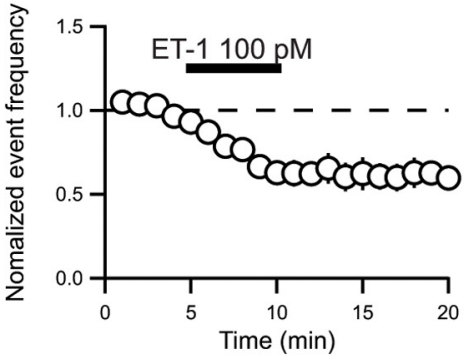

$\mathrm{H}$

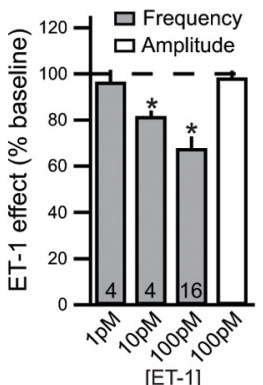

Figure 1. Endothelin-1 decreases the frequency of spontaneous EPSCs in vasopressinergic cells. $\boldsymbol{A}$, infrared differential interference contrast (IR-DIC), eGFP and merged (left to right) images showing whole-cell patch-clamping of an eGFP-positive neuron from a VP-eGFP-expressing transgenic rat. $\boldsymbol{B}$, Sample trace of the current-voltage (I-V) relationship from a VP-eGFP-positive neuron in response to voltage steps from -40 to $-130 \mathrm{mV}$. C, Mean I-V curve of VP neurons identified by either a linear I-V curve and/or the presence of eGFP. D, Representative traces of sEPSCs during control and following bath application of ET-1 (100 pM). $\boldsymbol{E}$, Time course of ET-1-mediated decrease in SEPSC frequency. $F, G$, Cumulative fraction plots demonstrate that ET-1 significantly increases the interevent interval ( $\boldsymbol{F}$; Kolmogorov-Smirnov test, $p=0.0001$ ), without an effect on event amplitude ( $\mathbf{G}$; Kolmogorov-Smirnov test, $p=0.29$ ). Inset shows averaged sEPSCs in control and after ET- 1 illustrating that ET-1 did not affect sEPSC amplitude. $\boldsymbol{H}$, Dose-response plot of ET-1 effects on quantal event frequency and summary of effects of ET-1 (100 pM) on event amplitude. Numbers in bars indicate $n .{ }^{*} p<0.05$.

rectifying current when given voltage steps ranging from -40 to -130 $\mathrm{mV}$ (Stern and Armstrong, 1995; Hirasawa et al., 2003), and in the transgenic eGFP-VP Wistar rats also by the absence or presence of eGFP, respectively. Recordings in voltage-clamp mode were continuously monitored with a $20 \mathrm{mV}$ hyperpolarizing pulse $(250 \mathrm{~ms})$ applied every $30 \mathrm{~s}$ throughout the experiment, and the steady-state current and amplitude of the capacitance transient were monitored as measures of input resistance and series/access resistance, respectively. Membrane currents were recorded without series resistance compensation. All recordings were accepted when access resistance was $<20 \mathrm{M} \Omega$ and changes were 
A
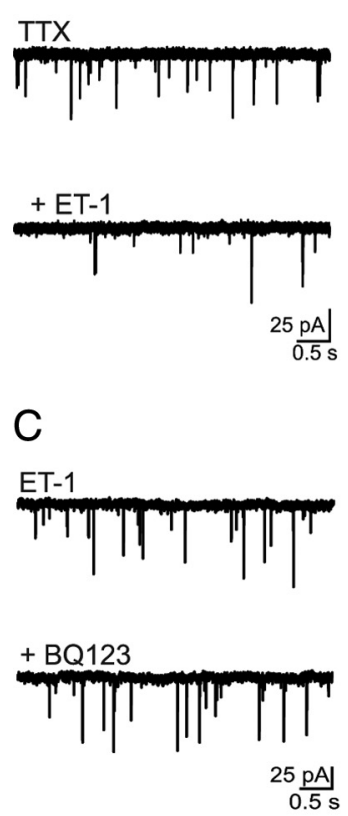
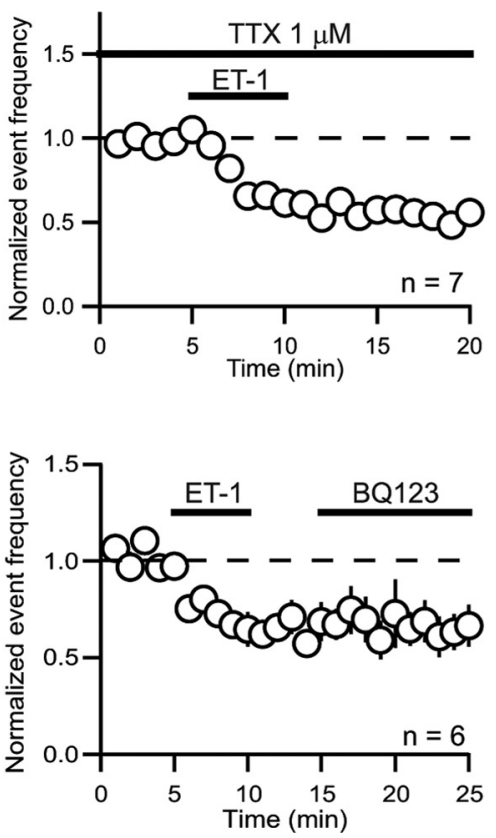

B
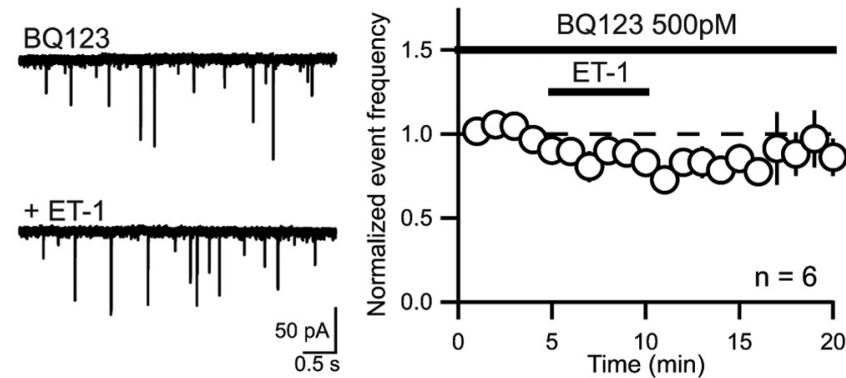

D
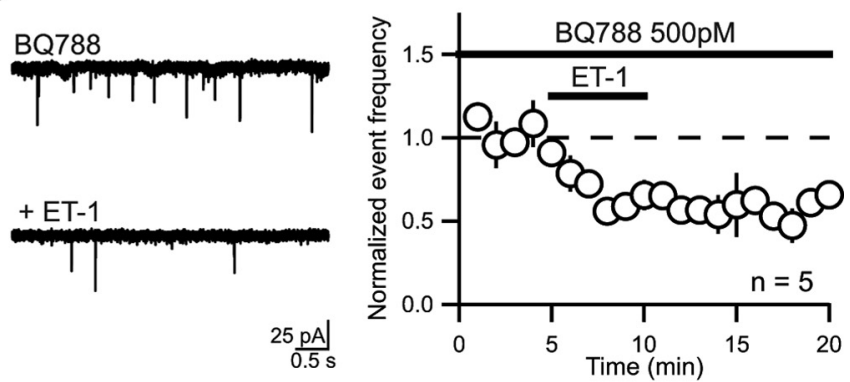

Figure 2. ET-1 depresses $m E P S C$ frequency onto VP neurons via $E_{A}$ receptors. $A-D$, Example traces (left) and time course plots (right) illustrating the effect of ET-1 on quantal event frequency

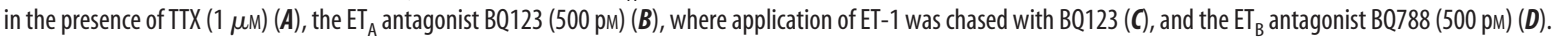

limited to $<15 \%$. For all experiments, picrotoxin $(50 \mu \mathrm{M})$ was added to the ACSF to block $\mathrm{GABA}_{\mathrm{A}}$-mediated synaptic currents, and neurons were voltage-clamped at $-80 \mathrm{mV}$. The majority of spontaneous EPSC (sEPSC) recordings were performed without tetrodotoxin (TTX) except where indicated otherwise. Spontaneous quantal glutamate release is TTX insensitive in the SON (Kombian et al., 2000a); however, to be confident that they are not action potential driven, TTX $(1 \mu \mathrm{M})$ was included in a portion of the neurons examined after MNC identification. In addition, some neurons were recorded using the cell-attached mode without TTX in the ACSF.

Signals were amplified using a Multiclamp 700B amplifier (Molecular Devices), low-pass filtered at $1 \mathrm{kHz}$, and digitized at $10 \mathrm{kHz}$. Data were collected (pClamp 9; Molecular Devices) and stored on a computer for off-line analysis with software designed to detect quantal synaptic events (MiniAnalysis; Synaptosoft). The amplitude and frequency of quantal events was obtained during a 3 min control period, the last 3 min of ET-1 application, and following at least $10 \mathrm{~min}$ of wash. Between 250 and 500 synaptic events were selected for cumulative probability plots. All cells in a given dataset were averaged and are presented as the mean \pm SEM. Statistical analyses were performed using a two-tailed Student's $t$ test when comparing two groups, a one-way ANOVA with a Newman-Keuls or Tukey's post hoc test for comparisons across multiple groups, and Kolmogorov tests for comparing two cumulative distributions. $p<0.05$ was accepted as statistically significant.

Two-photon calcium imaging. Slices were transferred to a recording chamber and astrocytes in the SON were loaded with the $\mathrm{Ca}^{2+}$ indicator Rhod-2-AM (10-100 $\mu \mathrm{M})$ (Invitrogen) using an adapted multicell bolusloading technique targeted into the SON (Garaschuk et al., 2006). Fluorescence levels in stained cells were allowed to stabilize for at least $1 \mathrm{~h}$ before imaging experiments were performed. Calcium transients were imaged on a custom-built, two-photon laser-scanning microscope fitted with a LUMPLFL $40 \times$ W/IR-2 water-immersion objective. We use a modified Olympus BX51WIF upright research microscope equipped with infrared-compatible optics and an Ultima -X-Y laser-scanning module (Prairie Technologies) that is directly coupled to a Mai Tai XF Ti:Sapphire laser source (Spectra-Physics).

The Rhod-2 fluorophore was excited at $835-840 \mathrm{~nm}$, and the epifluorescence detected with external detectors fitted with a $605 \mathrm{~nm}(55 \mathrm{~nm}$ bandpass) emission filter. Images were acquired between 50 and $100 \mu \mathrm{m}$ below the surface of the slice. Image series were analyzed off-line and calcium transients were quantified using ImageJ software. Fluorescence signals were defined as $\Delta F / F=\left[\left(F_{1}-B_{1}\right)-\left(F_{0}-B_{0}\right)\right] /\left(F_{0}-B_{0}\right)$, where $F_{1}$ and $F_{0}$ are fluorescence in the astrocyte at any given time point and at the beginning of the experiment, respectively, and $B_{1}$ and $B_{0}$ are the background fluorescence at the same time point and at the beginning of the experiment, respectively. Background values were taken from an adjacent area located at least $10 \mu \mathrm{m}$ from imaged areas.

Chemical compounds. ET-1 was purchased from Bachem. AM251 (N(piperidin-1-yl)-5-(4-iodophenyl)-1-(2,4-dichlorophenyl)-4-methyl-1 $H$-pyrazole-3-carboximide), BQ123 (cyclo(D-Trp-D-Asp-Pro-D-Val-Leu), and BQ788 ( $N$-[(cis-2,6-dimethyl-1-piperidinyl)carbonyl $]$-4-methyl-Lleucyl-1-(methoxycarbonyl)-D-tryptophyl-D norleucine sodium salt) picrotoxin were purchased from Tocris Bioscience. Tetrodotoxin was purchased from Alomone Labs. BAPTA (glycine, N,N'-(1,2-ethanediylbis(oxy-2,1-phenylene) )bis( $\mathrm{N}$-(carboxymethyl))-, tetrapotassium salt) was purchased from Invitrogen.

\section{Results}

Whole-cell patch-clamp recordings were obtained from MNCs in the SON identified on the basis of their location, morphology, and the presence of a delayed onset to action potential generation in response to depolarizing current injection (Tasker and Dudek, 1991). MNCs were further classified into either OT- or VPcontaining neurons based on previously described electrical properties of immunohistochemically identified MNCs (Stern and Armstrong, 1995; Hirasawa et al., 2003): OT neurons display an outward rectification at negative potentials, whereas VP neurons display a linear current-voltage relationship. In some experiments, recordings were obtained from hypothalamic slices prepared from transgenic Wistar rats expressing VP-eGFP (Ueta et al., 2005) to further verify the identity of either VP or OT MNCs based on the presence or absence, respectively, of eGFP fluorescence. All 16 cells identified as VP-eGFP positive had a linear current-voltage curve (Fig. $1 A-C$ ), whereas the majority of cells that were negative for eGFP fluorescence displayed sustained outward rectification (see Fig. $4 A-C$ ). While not all neurons 
identified as OT containing based on the absence of eGFP had a rectifying currentvoltage relationship, it is possible that eGFP was not expressed in detectable quantities because the transgenic rats were heterozygous and contained varying copies of the VP-eGFP transgene (10-100 copies) (Ueta et al., 2005). The strong correlation of a linear current-voltage curve to eGFP expression or post hoc immunohistochemistry (Hirasawa et al., 2003) suggests that use of electrophysiological fingerprints is an accurate protocol for determining MNC phenotypes. Thus, MNCs were largely classified as OT or VP based on their current-voltage relationship.

\section{Endothelin-1 depresses glutamatergic} transmission onto VP neurons

MNCs in vitro receive a relatively high rate of quantal input compared with most cortical regions $(2.64 \pm 0.28 \mathrm{~Hz} ; n=85)$ (Gordon and Bains, 2003), and increases in mEPSC frequency can lead to increases in firing frequency (Kombian et al., $2000 \mathrm{~b})$. This suggests that quantal glutamate release conveys important information that influences VP and OT release from MNCs. To determine whether ET-1 modulates glutamatergic synaptic inputs onto MNCs, we bath applied ET-1 (1 nM to $1 \mu \mathrm{M}$ ) and assessed changes in both the amplitude and frequency of quantal events. However, at these concentrations we observed significant vasoconstriction of large blood vessels in the SON that compromised the stability of patch-clamp recordings. At ET-1 concentrations of $\leq 100 \mathrm{pM}$, vasoconstriction or movement in the slice was no longer observed enabling us to record for long periods of time (>20 min) without changes in whole-cell access resistance.

In MNCs classified as VPergic, we observed a decrease in the frequency of quantal glutamate release following bath application of ET- 1 for $5 \mathrm{~min}(100 \mathrm{pM}$; $69.38 \pm 4.40 \%$ of control; $n=16 ; p<0.001$ ) (Fig. $1 D-F, H)$. There were no changes in the amplitude of quantal events $(98.14 \pm 2.51 \%$ of control; $p>0.05$ ) (Fig. $1 G, H$ ), suggesting that ET-1 had a presynaptic locus of action. The decrease in quantal event frequency reached a stable level and following wash of ET-1 persisted for the remainder of the recording $(>20 \mathrm{~min})$. The effect of ET-1 on quantal event frequency was dose dependent because a concentration of $10 \mathrm{pM}$ produced a smaller but significant decrease ( $81.48 \pm 2.63 \%$ of control; $n=4 ; p<0.05)$, whereas 1 pM was without effect $(96.41 \pm 5.34 \%$ of control; $n=4 ; p>$ 0.05 ) (Fig. $1 H$ ). There were no changes in the baseline resting membrane potential following application of ET-1 (98.79 \pm $2.06 \%$ of control; $n=6 ; p>0.05$ ).

While previous studies have demonstrated that glutamatergic quantal events onto MNCs are TTX insensitive (Kabashima et al., 1997; Kombian et al., 2000a), it was necessary to verify that the ET-1-mediated depression in sEPSC frequency was action potential independent. Consistent with previous findings, application of TTX $(1 \mu \mathrm{M})$ did not change the amplitude or frequency of
B

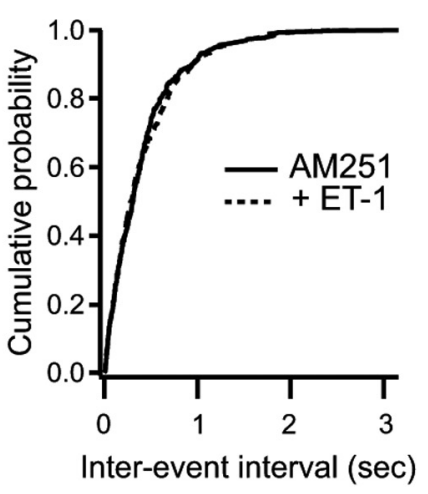

C

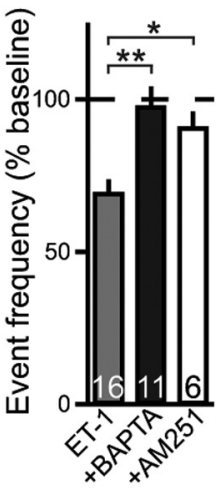

Figure 3. ET-1-mediated depression of EPSC frequency in VP neurons is via a retrograde messenger. $\boldsymbol{A}$, Cumulative fraction plot

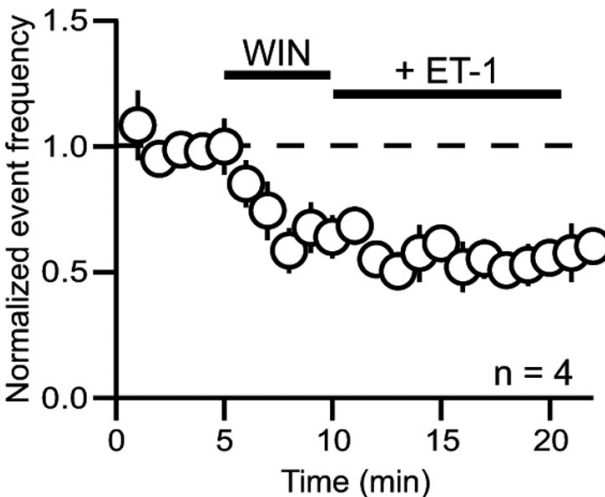

Time (min) antart 251 (1 (percentage of baseline) in control (gray bar), with intracellular BAPTA (black bar), and in the presence of AM251 (white bar). $\boldsymbol{D}$, Example traces (left) and time course plot (right) illustrating the effect of ET-1 on quantal event frequency after bath application of the CB1 receptor agonist WIN $(1 \mu \mathrm{M})$.

mEPSCs (data not shown). In the presence of TTX, the depression of mEPSC frequency in VP MNCs after application of ET-1 (100 pM) was not significantly different compared with the depression observed under control conditions $(65.81 \pm 4.39 \%$ of control; $n=7 ; p>0.05$ compared with ET-1 under control conditions) (Fig. $2 A$ ). Since blocking action potential firing had no effect on the ET-1-mediated depression of sEPSCs, the following experiments were performed in the absence of TTX. To further pharmacologically characterize the effects of ET-1 on quantal release in VP neurons, ET subtype-selective receptor antagonists were bath applied. In the presence of BQ123 (500 pM), a selective $\mathrm{ET}_{\mathrm{A}}$ receptor antagonist, ET-1 failed to depress sEPSC frequency $(90.41 \pm 3.13 \%$ of control; $n=6 ; p<0.01$ compared with ET-1 without antagonist) (Fig. 2B). The ET-1-mediated persistent depression of sEPSC frequency was not due to slow unbinding of agonist to its receptor as a BQ123 chaser after application of ET-1 failed to reverse the depression (99.07 \pm $6.12 \%$ of ET- $1 ; n=6 ; p>0.05$ ) (Fig. $2 C$ ). This raises the possibility that receptor occupation by the agonist establishes an intracellular biochemical cascade whose time course outlasts receptor occupancy. Conversely, application of the $\mathrm{ET}_{\mathrm{B}}$ subtype-specific receptor antagonist BQ788 (500 pM) failed to block the ET-1-mediated depression in sEPSC frequency ( $60.43 \pm 5.68 \%$ of control; $n=5 ; p>0.05$ compared with ET-1 without antagonist) (Fig. 2D). 
A

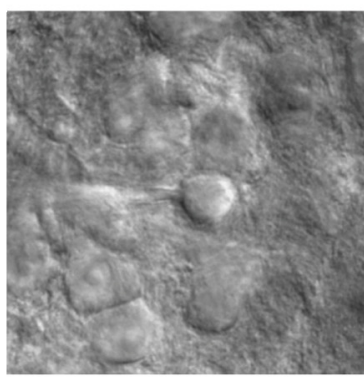

B

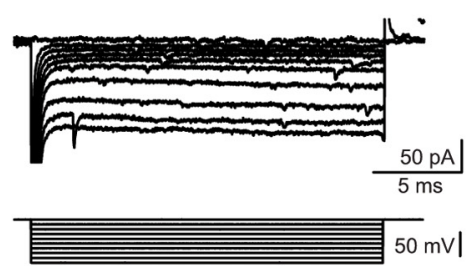

D

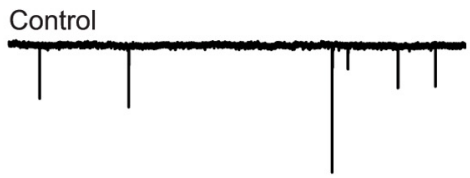

ET-1

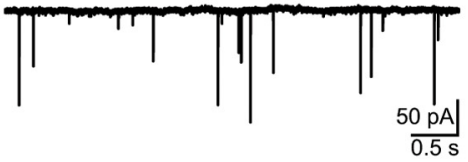

$\mathrm{F}$

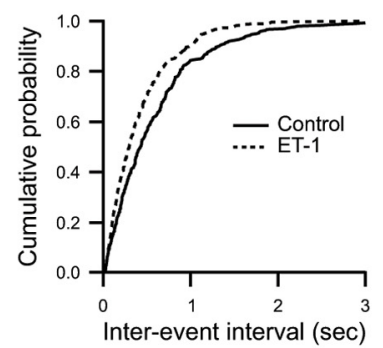

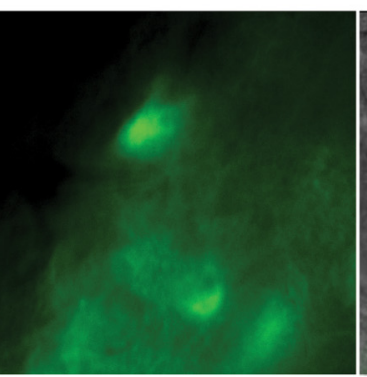

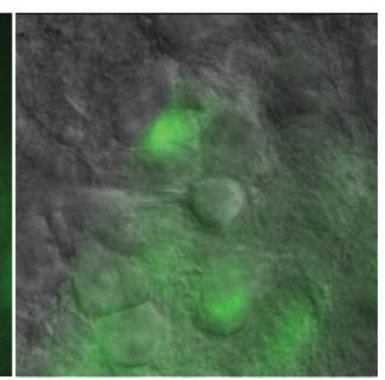

\section{C}

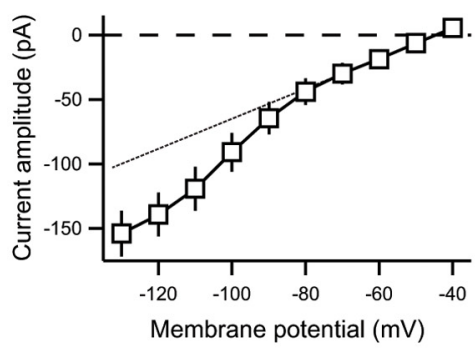

E

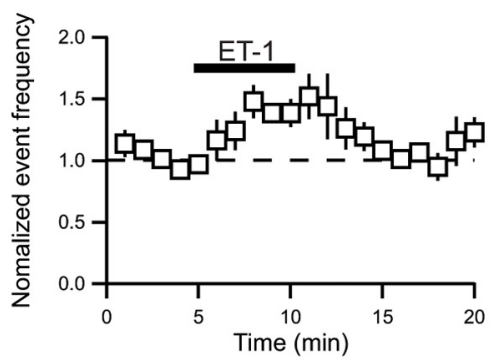

G

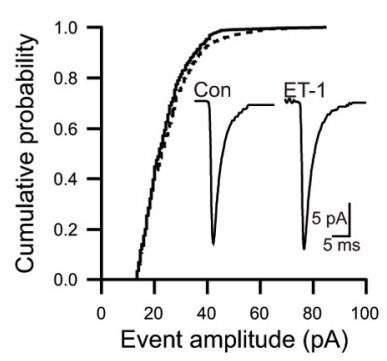

Figure 4. ET-1 increases the frequency of spontaneous EPSCs in OT-containing neurons. $\boldsymbol{A}$, infrared differential interference contrast (IR-DIC), eGFP, and merged (left to right) images showing whole-cell patch-clamping of an eGFP-negative neuron from a VP-eGFP-expressing transgenic rat. $\boldsymbol{B}$, Sample trace of a current-voltage relationship from a VP-eGFP-negative neuron in response to voltage steps from -40 to $-130 \mathrm{mV}$. C, Mean current-voltage curve from 0T neurons identified by either a rectifying $\mathrm{I}-\mathrm{V}$ curve and/or the absence of eGFP. D, Representative traces of sEPSCs during control and following bath application of ET-1 (100 pm). $\boldsymbol{E}$, Time course of ET-1-mediated increase in quantal event frequency. $\boldsymbol{F}, \mathbf{G}$, Cumulative fraction plots demonstrate that ET-1 significantly decreased sEPSC interevent intervals ( $\boldsymbol{F}$; Kolmogorov-Smirnov test, $p=0.04$ ), but not amplitudes (G; KolmogorovSmirnov test, $p=0.25$ ). Inset shows averaged sEPSC in control and after ET-1.

Since the decrease in sEPSC frequency suggests that the ET-1 effect on VP neurons has a presynaptic locus of expression, we tested for the possible involvement of a retrograde messenger (Hirasawa et al., 2004; Oliet et al., 2007; Kuzmiski et al., 2009). As synthesis of many retrograde messengers is $\mathrm{Ca}^{2+}$ sensitive (Regehr et al., 2009), loading of the postsynaptic neuron with the calcium chelator BAPTA via the patch pipette to attenuate the release of a retrograde messenger is a well established way to identify involvement of such a messenger. We found that intracellular BAPTA (10 mM) prevented the ET-1-induced decrease in sEPSC frequency $(97.73 \pm 6.43 \%$ of control; $n=11 ; p<0.01$ compared with ET-1 in control conditions) (Fig. $3 A, C)$. Endo- cannabinoids (eCBs) are a likely candidate to mediate the retrograde inhibition of glutamate release onto VP neurons. To specifically test whether eCBs are required, we applied the cannabinoid $1(\mathrm{CB} 1)$ receptor antagonist $\mathrm{N}$-(piperidin-1-yl)-5-(4-iodophenyl)-1-(2,4-dichlorophenyl)-4-methyl-1 $H$-pyrazole-3-carboximide (AM251; $1 \mu \mathrm{M}$ ) to a further group of cells. AM251 blocked the reduction of sEPSC frequency induced by ET-1 ( $90.88 \pm 5.09 \%$ of control; $n=6 ; p<0.05$ compared with ET- 1 in control conditions) (Fig. $3 B, C$ ). Finally, if ET-1 is inducing the release of eCBs to depress glutamate release, then prior application of the $\mathrm{CB} 1$ receptor agonist WIN 55,212-2 (WIN, $1 \mu \mathrm{M}$ ) should occlude the action of ET-1. In this case, bath application of WIN depressed the frequency of sEPSCs in VP neurons and subsequent application of ET-1 was unable to mediate a further depression (WIN: $63.40 \pm$ $7.20 \%$ of control; ET-1: $55.66 \pm 6.48 \%$ of control; $n=4 ; p>0.05)$ (Fig. 3D).

\section{Endothelin-1 stimulates glutamatergic} transmission onto OT neurons

In contrast to VP-containing neurons, MNCs that displayed an OT-like electrophysiological fingerprint and/or did not express eGFP (Fig. 4A-C), displayed a robust, transient increase in the frequency of quantal glutamate release following exposure to ET-1 ( $5 \mathrm{~min}, 100 \mathrm{pM}, 145.80 \pm$ $5.83 \%$ of control; $n=11 ; p<0.01$ ) (Fig. $4 D-F)$. There was no change in the amplitude of quantal events observed during ET-1 treatment (100.3 $\pm 3.20 \%$ of control; $p>0.05$ ) (Fig. 4G). In addition, there were no changes in the baseline postsynaptic resting membrane potential following application of ET-1 $(99.59 \pm 3.18 \%$ of control; $n=5 ; p>0.05)$.

To pharmacologically characterize the ET-1 effects on OT neurons, we applied a similar approach to that described above with VP neurons. Interestingly, the increase in quantal event frequency induced by ET-1 (100 pM) on OT cells was completely abolished in the presence of TTX $(1 \mu \mathrm{M} ; 93.77 \pm 3.06 \%$ of control; $n=7$; $p<0.001$ compared with ET-1 in control conditions) (Fig. 5A), suggesting that this effect is dependent on action potential firing. In contrast to the ET-1-mediated decrease in quantal event frequency on VP neurons, the excitatory effect of ET-1 on OT cells was not dependent on $\mathrm{ET}_{\mathrm{A}}$ receptor activation as $\mathrm{BQ} 123$ failed to prevent the increase in sEPSC frequency $(126.30 \pm 5.09 \%$ of control; $n=7 ; p>0.05$ compared with ET-1 in control conditions). However, the $\mathrm{ET}_{\mathrm{B}}$ receptor antagonist $\mathrm{BQ788}$ completely blocked the increase in event frequency $(97.88 \pm 7.80 \%$ of control; $n=5 ; p<0.001$ compared with ET-1 in control conditions) (Fig. 5C). To investigate whether the increase in sEPSC frequency onto OT neurons also involved the release of a retrograde mes- 
A
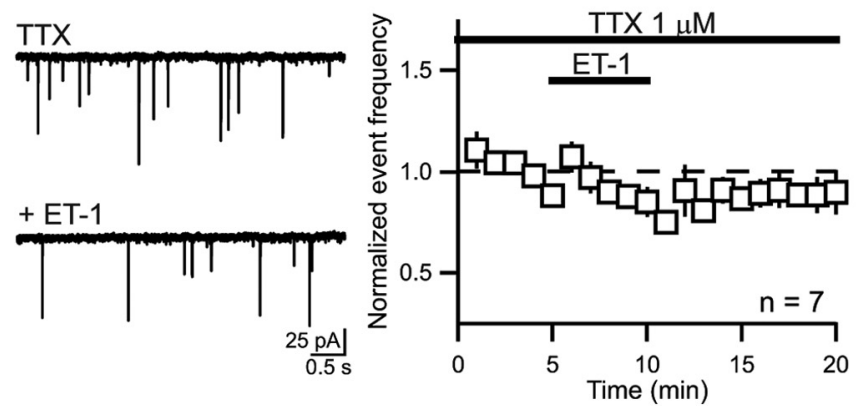

C
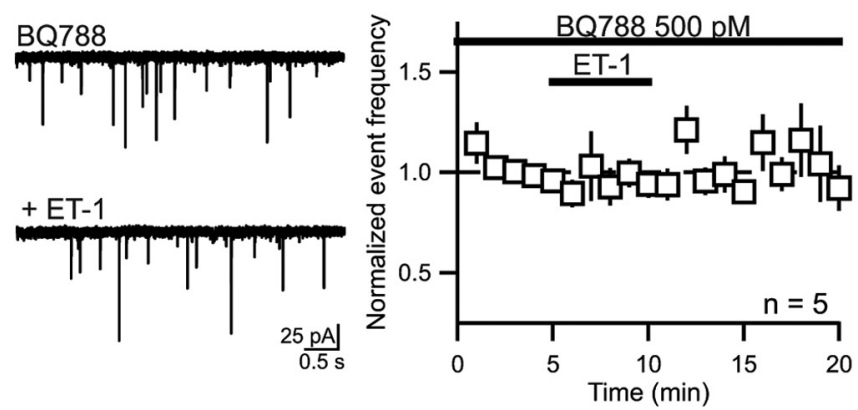

$\mathrm{B}$
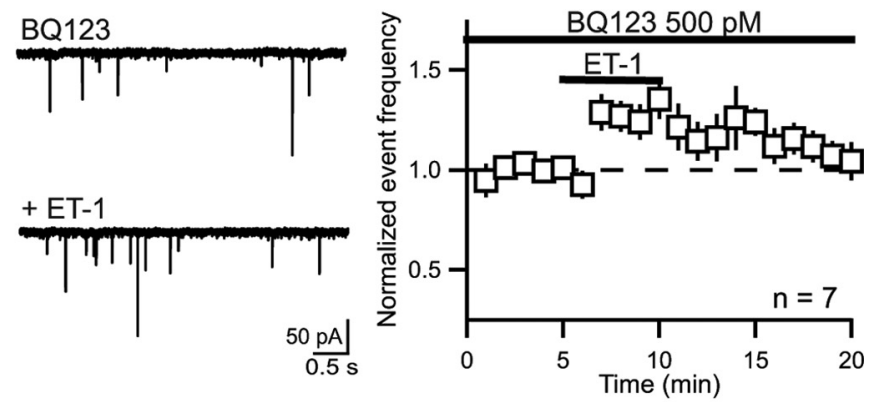

D
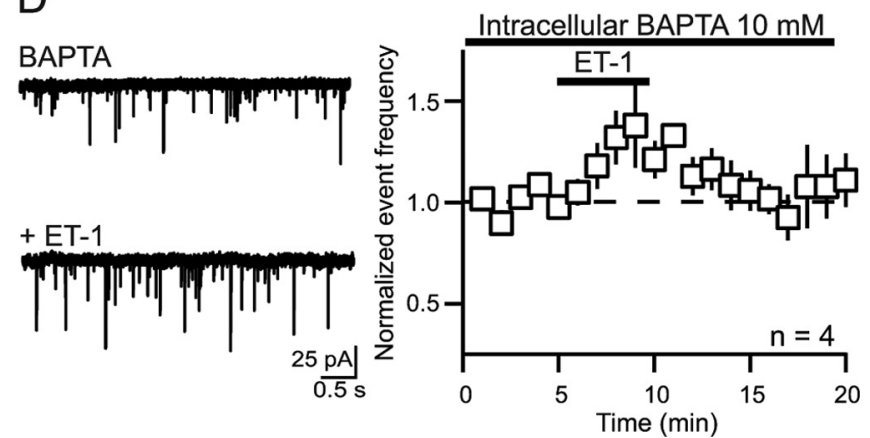

Figure 5. ET-1 stimulates $s \mathrm{EPSC}$ frequency onto $0 \mathrm{~T}$ neurons via $\mathrm{ET}_{B}$ receptor stimulation. $\boldsymbol{A}-\boldsymbol{D}$, Example traces (left) and time course plots (right) illustrating the effect of $\mathrm{ET}-1$ on quantal event frequency in the presence of TTX $(\boldsymbol{A})$, the $\mathrm{ET}_{\mathrm{A}}$ antagonist $\mathrm{BQ123}(\boldsymbol{B})$, the $\mathrm{ET}_{B}$ antagonist $\mathrm{BQ788}(\boldsymbol{C})$, and when BAPTA (10 mM) was included in the patch pipette $(\boldsymbol{D})$.

senger similar to that observed in VP neurons, we loaded the postsynaptic neuron with BAPTA (10 mM). In this case however, BAPTA failed to prevent the ET-1-mediated increase in sEPSC frequency onto OT neurons $(136.10 \pm 11.27 \%$ of control; $n=4)$ (Fig. 5D), suggesting that neither a retrograde messenger nor a rise in postsynaptic $\mathrm{Ca}^{2+}$ is required.

Both $\mathrm{ET}_{\mathrm{A}}$ and $\mathrm{ET}_{\mathrm{B}}$ receptors are highly expressed in astrocytes in vivo and in culture (Schinelli et al., 2001). Application of ET-1 has been shown to induce rises in intracellular $\mathrm{Ca}^{2+}$ in hippocampal astrocytes (Blomstrand et al., 1999; Fiacco et al., 2007), and elevations in intracellular $\mathrm{Ca}^{2+}$ can result in the release of gliotransmitters such as glutamate, ATP, or D-serine that modulate synaptic transmission (Agulhon et al., 2008; Henneberger et al., 2010). To investigate a possible role for astrocytes in the ET1 -mediated modulation of quantal glutamate release onto MNCs, we imaged $\mathrm{Ca}^{2+}$ transients in astrocytes in response to application of ET-1 using two-photon imaging (Fig. 6). Astrocytes were bulk loaded with the $\mathrm{Ca}^{2+}$ indicator Rhod-2 AM. Astrocytes in the SON displayed spontaneous $\mathrm{Ca}^{2+}$ elevations; however, there were no significant elevations in intracellular $\mathrm{Ca}^{2+}$ signaling when ET-1 was applied (100 pM, $3.0 \pm 3.6 \% ; n=$ 7, 94 astrocytes; $10 \mathrm{nM},-2.4 \pm 3.1 \% ; n=6,79$ astrocytes; 100 $\mathrm{nM}, 9.2 \pm 9.7 \% ; n=7,114$ astrocytes) at concentrations adequate to produce changes in quantal glutamate release onto MNCs. In addition, at $100 \mathrm{~nm}$, as we reported for the electrophysiological experiments, we sometimes observed vascular constrictions, indicating that ET-1 was capable of stimulating vascular receptors while still being ineffective at elevating $\mathrm{Ca}^{2+}$ in astrocytes. As an additional positive control, $\mathrm{Ca}^{2+}$ transients in response to application of $10 \mathrm{~nm}$ ET-1 were imaged in hippocampal astrocytes (188 $\pm 19 \% ; n=4,106$ astrocytes). Therefore, it is highly unlikely that a gliotransmitter contributes to the ET-1 effects on synaptic transmission.

\section{Endothelin-1 increases firing in OT neurons but not VP neurons}

Finally, to directly test whether ET-1 has an effect on the firing activity of MNCs, we performed tight-seal cell-attached recordings. ET-1 had no effect on the activity of VP neurons (101.9 \pm $30.1 \%$ of control; $n=5 ; p>0.05)$, indicating that $\mathrm{CB}$ release has little effect on MNC spiking, as previously reported (Sabatier and Leng, 2006). In contrast, ET-1 significantly increased the spiking of OT neurons ( $226.8 \pm 66.6 \%$ of control; $n=7 ; p<0.05$ ) (Fig. $7 A-C)$.

\section{Discussion}

The present study provides compelling evidence that endothelin, at concentrations subthreshold for vascular effects, can modulate excitatory synaptic transmission in the SON. Activation of $\mathrm{ET}_{\mathrm{A}}$ receptors on $\mathrm{VP}$-containing $\mathrm{MNCs}$ causes release of eCBs that act as a retrograde messenger, resulting in a reduced frequency of quantal glutamate release. In contrast, the frequency of sEPSCs onto OT-containing neurons was enhanced in response to $\mathrm{ET}_{\mathrm{B}}$ receptor activation. This enhancement was dependent on action potential firing and, therefore, likely involves the stimulation of afferent neurons.

We demonstrate here that $\mathrm{ET}_{\mathrm{A}}$ receptor-mediated production of eCBs retrogradely inhibits glutamate release onto VP neurons in the SON. Although ET-1 has been shown to induce VP secretion from terminals in the neurohypophysis (Ritz et al., 1992; Rossi, 1993, 2004; Rossi et al., 1997), previous studies using a compartmentalized hypothalamo-neurohypophysial explant have shown that $\mathrm{ET}_{\mathrm{A}}$ receptor stimulation at a hypothalamic site inhibited VP release (Rossi, 1995, 2004). Accordingly, extracellular recordings of phasically firing MNCs in the SON (characteristic of VP neurons) demonstrated that a majority of neurons 


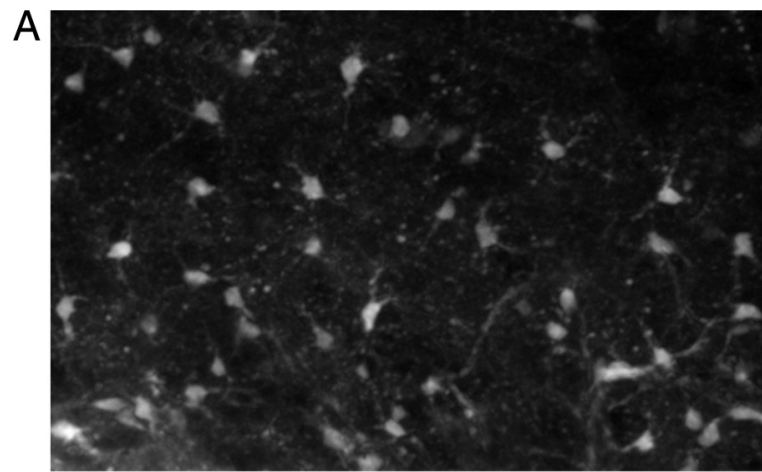

B

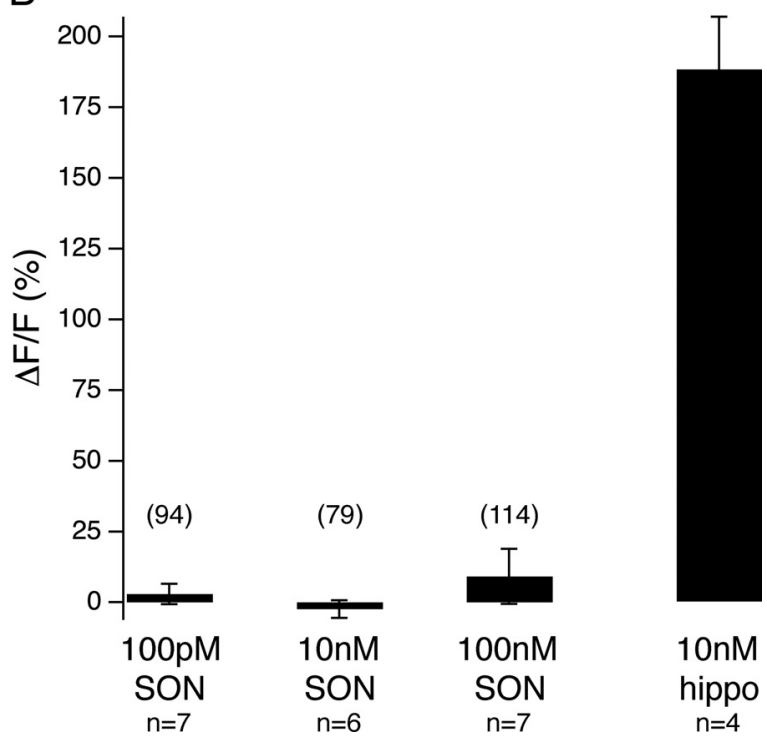

Figure 6. ET-1 does not elicit astrocyte intracellular $\mathrm{Ca}^{2+}$ signaling in the SON. A, Twophoton image projection showing astrocytes in the SON selectively loaded with the $\mathrm{Ca}^{2+}$ indicator Rhod-2. $\boldsymbol{B}$, Bar graph summary of astrocyte $\mathrm{Ca}^{2+}$ imaging experiments showing that astrocyte fluorescence remains unchanged in the SON with ET-1 application (100 pM-100 nm), while in the hippocampus, ET-1 application causes dramatic increases in astrocyte intracellular $\mathrm{Ca}^{2+}$ signaling.

were inhibited by ET-1 (Yamamoto et al., 1993). The current study provides a mechanism to explain these early observations.

Previous studies have shown that eCBs can modulate synaptic transmission onto MNCs following both high-frequency activity and stimulation of various G-protein-coupled receptors (Hirasawa et al., 2004; Di et al., 2005a,b; Malcher-Lopes et al., 2006; Oliet et al., 2007; Kuzmiski et al., 2009). ET-1 can stimulate release of the eCBs, 2-arachidonoyl glycerol (2-AG) and anandamide from astrocytes (Walter et al., 2002; Walter and Stella, 2003); however, both $2-\mathrm{AG}$ and anandamide production are $\mathrm{Ca}^{2+}$-dependent processes, and the absence of a rise in intracellular $\mathrm{Ca}^{2+}$ after ET-1 argues against a role for astrocytes. Instead, our results point to a postsynaptic location for $\mathrm{ET}_{\mathrm{A}}$ receptors and $\mathrm{eCB}$ production as inclusion of BAPTA in the patch pipette to block postsynaptic rises in $\mathrm{Ca}^{2+}$ prevented the depression in sEPSC frequency. In support of a postsynaptic location for $\mathrm{ET}_{\mathrm{A}}$ receptors are anatomical studies in which $\mathrm{ET}_{\mathrm{A}}$ receptor immunoreactivity (Kurokawa et al., 1997) or binding sites (Kohzuki et al., 1991) were demonstrated in cell bodies of the SON. The eCB depression of sEPSCs via CB1 receptors is not mediated by actions on voltage-gated $\mathrm{Ca}^{2+}$ currents (Hirasawa et al., 2004; Di et al., 2005b) because ET-1 (via eCBs) suppressed action potential-
A

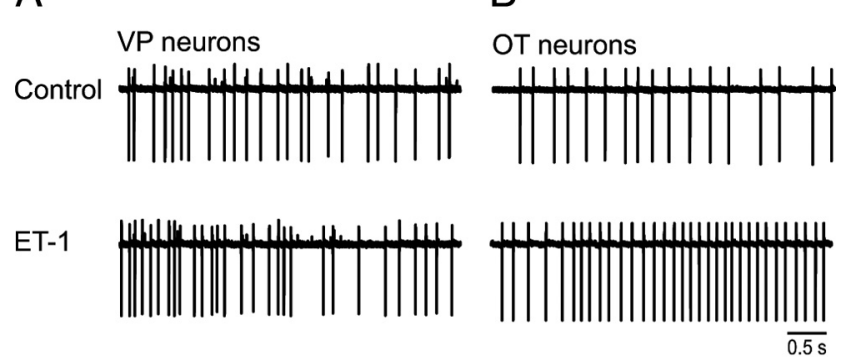

C

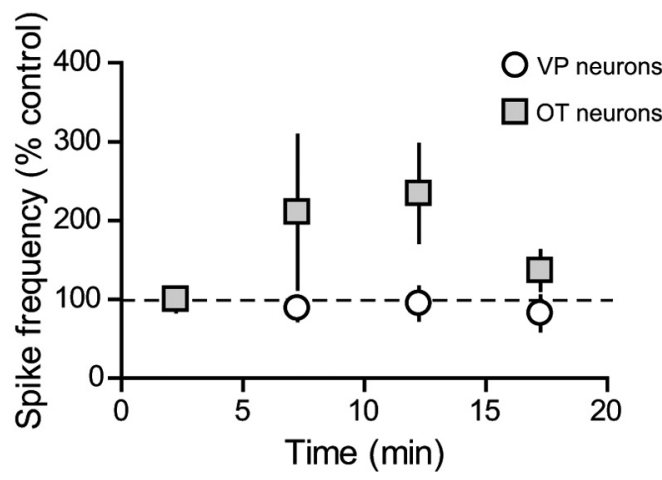

Figure 7. ET-1 increases firing in OT neurons but does not affect VP neurons. $A, B$, Cellattached recordings showing effects of bath application of ET- 1 in VP neurons $(n=5)(\boldsymbol{A})$ and OT neurons $(n=7)(\boldsymbol{B})$. C, Summary data showing that ET-1 increased firing in 0T neurons, but did not affect spiking activity in VP neurons.

independent glutamate release. Quantal glutamate release in the SON is not generally influenced by extracellular $\mathrm{Ca}^{2+}$ levels and is not dependent on $\mathrm{Ca}^{2+}$ influx through voltage-gated $\mathrm{Ca}^{2+}$ channels (Inenaga et al., 1998; Hirasawa et al., 2001). Thus, the eCB-mediated depression of quantal glutamate release is likely via a direct action on release machinery or an effect on intraterminal $\mathrm{Ca}^{2+}$ (Lovinger, 2008).

In contrast to the effect on VP neurons, application of ET-1 enhanced glutamate release from excitatory afferent fibers onto OT neurons in the SON. Consistent with our findings that $\mathrm{ET}_{\mathrm{B}}$ receptor stimulation enhances glutamate release onto OT neurons, central administration of ET-3 or ET-1 has been shown to elevate plasma levels of OT in the rat (Samson et al., 1991; Guzek et al., 1999). Interestingly, the effect of ET-1 on OT neurons was blocked by TTX, suggesting that ET-1 stimulated a presynaptic neuron. Although the present experiment does not identify the locus of the presynaptic excitatory neurons, most likely targets are the local glutamatergic interneurons around the SON (Boudaba et al., 1997). An excitatory action would be consistent with observations of excitatory actions of endothelin in the anteroventral third ventricular region (Yamamoto et al., 1993) and in the subfornical organ (Wall and Ferguson, 1992). The different responses of OT and VP neurons to ET-1 thus appear to be due to the fact that they activate different receptors $\left(\mathrm{ET}_{\mathrm{A}} \mathrm{vs}_{\mathrm{ET}}\right)$ and the fact that these receptors are on different cells. Whereas there is good evidence for $\mathrm{eCB}$ production in both OT and VP neurons (Kuzmiski et al., 2009), the absence of $\mathrm{ET}_{\mathrm{B}}$ receptors on the OT cells (or at least the fact they are not coupled to rises in intracellular $\mathrm{Ca}^{2+}$ in these cells) accounts for the lack of ET-1-mediated $\mathrm{eCB}$ action on OT neurons. The differential response is in line with previous findings (Oliet et al., 2007) that eCBs act within a limited diffusion distance as the eCBs emanating from VP neurons do not appear to affect synapses impinging upon OT neu- 
rons, despite the fact that the excitatory terminals possess CB1 receptors (Hirasawa et al., 2004).

Endothelin has previously been shown to induce elevations in astrocytic $\mathrm{Ca}^{2+}$ in the hippocampus and striatum (Blomstrand et al., 1999; Fiacco et al., 2007). Interestingly, we show that SON astrocytes were insensitive to ET-1 at concentrations sufficient to modulate synaptic transmission (100 pM) and even at higher concentrations $(\geq 10 \mathrm{nM}$ ) were relatively unresponsive compared with other cortical areas where ET-1 is a potent stimulant of astrocytic $\mathrm{IP}_{3}$ production and subsequent $\mathrm{Ca}^{2+}$ elevations (Venance et al., 1997, 1998; Blomstrand et al., 1999; Fiacco et al., 2007). The release of gliotransmitters is linked to elevations in astrocyte $\mathrm{Ca}^{2+}$; thus, it is unlikely that the increase in sEPSC frequency in OT neurons we observed following application ET-1 is mediated by astrocyte-to-neuron communication. Indeed, Fiacco et al. (2007) also reported that ET-1-mediated $\mathrm{Ca}^{2+}$ rises in astrocytes did not modulate hippocampal synaptic transmission. Our results add to a growing list of transmitters, such as glutamate, GABA, serotonin, angiotensin, carbachol, VP, and OT, that do not induce elevations in astrocyte $\mathrm{Ca}^{2+}$ in the SON or only produce relatively small transients (norepinephrine and ATP) (Espallergues et al., 2007).

VP and OT are released in response not only to relevant osmotic and reproductive stimuli, but also in response to a variety of emotional, physiological, and immunological stressors. Of particular interest is the fact that individual stimuli may cause the release of one of the neurohypophysial peptides, whereas the release of the other will be largely unaffected. For example, exposure to a novel environment significantly reduces plasma VP, whereas plasma OT is unchanged (Douglas et al., 2003). The opposing actions of ET-1 on VP and OT neurons that we report in this study would be well suited to mediate such differential action. In this regard, ET-1 has been implicated as a neurotransmitter or neuromodulator of CNS autonomic responses to several varieties of stressors (Kurihara et al., 2000). As alterations in afferent excitatory inputs (Nissen et al., 1995) are particularly important in sculpting the activity of MNCs, ET-1 may be a possible neurotransmitter underlying selective release of the neurohypophysial hormones.

\section{References}

Agulhon C, Petravicz J, McMullen AB, Sweger EJ, Minton SK, Taves SR, Casper KB, Fiacco TA, McCarthy KD (2008) What is the role of astrocyte calcium in neurophysiology? Neuron 59:932-946.

Alonso G, Gallibert E, Lafont C, Guillon G (2008) Intrahypothalamic angiogenesis induced by osmotic stimuli correlates with local hypoxia: a potential role of confined vasoconstriction induced by dendritic secretion of vasopressin. Endocrinology 149:4279-4288.

Blomstrand F, Giaume C, Hansson E, Rönnbäck L (1999) Distinct pharmacological properties of ET-1 and ET-3 on astroglial gap junctions and Ca2 + signaling. Am J Physiol 277:C616-C627.

Boudaba C, Schrader LA, Tasker JG (1997) Physiological evidence for local excitatory synaptic circuits in the rat hypothalamus. J Neurophysiol 77:3396-3400.

Dashwood MR, Loesch A (2010) Endothelin-1 as a neuropeptide: neurotransmitter or neurovascular effects? J Cell Commun Signal 4:51-62.

Davenport AP (2002) International Union of Pharmacology. XXIX. Update on endothelin receptor nomenclature. Pharmacol Rev 54:219-226.

Di S, Malcher-Lopes R, Marcheselli VL, Bazan NG, Tasker JG (2005a) Rapid glucocorticoid-mediated endocannabinoid release and opposing regulation of glutamate and $\gamma$-aminobutyric acid inputs to hypothalamic magnocellular neurons. Endocrinology 146:4292-4301.

Di S, Boudaba C, Popescu IR, Weng FJ, Harris C, Marcheselli VL, Bazan NG, Tasker JG (2005b) Activity-dependent release and actions of endocannabinoids in the rat hypothalamic supraoptic nucleus. J Physiol 569:751-760.
Douglas AJ, Brunton PJ, Bosch OJ, Russell JA, Neumann ID (2003) Neuroendocrine responses to stress in mice: hyporesponsiveness in pregnancy and parturition. Endocrinology 144:5268-5276.

Espallergues J, Solovieva O, Técher V, Bauer K, Alonso G, Vincent A, Hussy N (2007) Synergistic activation of astrocytes by ATP and norepinephrine in the rat supraoptic nucleus. Neuroscience 148:712-723.

Fiacco TA, Agulhon C, Taves SR, Petravicz J, Casper KB, Dong X, Chen J, McCarthy KD (2007) Selective stimulation of astrocyte calcium in situ does not affect neuronal excitatory synaptic activity. Neuron 54:611-626.

Garaschuk O, Milos RI, Konnerth A (2006) Targeted bulk-loading of fluorescent indicators for two-photon brain imaging in vivo. Nat Protoc $1: 380-386$.

Gordon GR, Bains JS (2003) Priming of excitatory synapses by $\alpha 1$ adrenoceptor-mediated inhibition of group iii metabotropic glutamate receptors. J Neurosci 23:6223-6231.

Guzek JW, Lewandowska A, Stempniak B (1999) Endothelin-1 and the release of neurohypophysial hormones under dehydration or haemorrhage. Pathophysiology 6:53-61.

Henneberger C, Papouin T, Oliet SH, Rusakov DA (2010) Long-term potentiation depends on release of $\mathrm{D}$-serine from astrocytes. Nature 463:232-236.

Hirasawa M, Kombian SB, Pittman QJ (2001) Oxytocin retrogradely inhibits evoked, but not miniature, EPSCs in the rat supraoptic nucleus: role of N- and P/Q-type calcium channels. J Physiol 532:595-607.

Hirasawa M, Mouginot D, Kozoriz MG, Kombian SB, Pittman QJ (2003) Vasopressin differentially modulates non-NMDA receptors in vasopressin and oxytocin neurons in the supraoptic nucleus. J Neurosci 23:4270-4277.

Hirasawa M, Schwab Y, Natah S, Hillard CJ, Mackie K, Sharkey KA, Pittman QJ (2004) Dendritically released transmitters cooperate via autocrine and retrograde actions to inhibit afferent excitation in rat brain. J Physiol 559:611-624.

Hrabovszky E, Liposits Z (2008) Novel aspects of glutamatergic signalling in the neuroendocrine system. J Neuroendocrinol 20:743-751.

Inenaga K, Honda E, Hirakawa T, Nakamura S, Yamashita H (1998) Glutamatergic synaptic inputs to mouse supraoptic neurons in calcium-free medium in vitro. J Neuroendocrinol 10:1-7.

Jourdain P, Israel JM, Dupouy B, Oliet SH, Allard M, Vitiello S, Theodosis DT, Poulain DA (1998) Evidence for a hypothalamic oxytocin-sensitive pattern-generating network governing oxytocin neurons in vitro. J Neurosci 18:6641-6649.

Kabashima N, Shibuya I, Ibrahim N, Ueta Y, Yamashita H (1997) Inhibition of spontaneous EPSCs and IPSCs by presynaptic GABAB receptors on rat supraoptic magnocellular neurons. J Physiol 504:113-126.

Kohzuki M, Chai SY, Paxinos G, Karavas A, Casley DJ, Johnston CI, Mendelsohn FA (1991) Localization and characterization of endothelin receptor binding sites in the rat brain visualized by in vitro autoradiography. Neuroscience 42:245-260.

Kombian SB, Mouginot D, Hirasawa M, Pittman QJ (2000a) Vasopressin preferentially depresses excitatory over inhibitory synaptic transmission in the rat supraoptic nucleus in vitro. J Neuroendocrinol 12:361-367.

Kombian SB, Hirasawa M, Mouginot D, Chen X, Pittman QJ (2000b) Short-term potentiation of miniature excitatory synaptic currents causes excitation of supraoptic neurons. J Neurophysiol 83:2542-2553.

Koseki C, Imai M, Hirata Y, Yanagisawa M, Masaki T (1989) Binding sites for endothelin-1 in rat tissues: an autoradiographic study. J Cardiovasc Pharmacol 13 [Suppl 5]:S153-S154.

Kurihara Y, Kurihara H, Morita H, Cao WH, Ling GY, Kumada M, Kimura S, Nagai R, Yazaki Y, Kuwaki T (2000) Role of endothelin-1 in stress response in the central nervous system. Am J Physiol Regul Integr Comp Physiol 279:R515-R521.

Kurokawa K, Yamada H, Ochi J (1997) Topographical distribution of neurons containing endothelin type A receptor in the rat brain. J Comp Neurol 389:348-360.

Kuzmiski JB, Pittman QJ, Bains JS (2009) Metaplasticity of hypothalamic synapses following in vivo challenge. Neuron 62:839-849.

Lovinger DM (2008) Presynaptic modulation by endocannabinoids. Handb Exp Pharmacol; 435-477.

MacCumber MW, Ross CA, Glaser BM, Snyder SH (1989) Endothelin: visualization of mRNAs by in situ hybridization provides evidence for local action. Proc Natl Acad Sci U S A 86:7285-7289.

Malcher-Lopes R, Di S, Marcheselli VS, Weng FJ, Stuart CT, Bazan NG, 
Tasker JG (2006) Opposing crosstalk between leptin and glucocorticoids rapidly modulates synaptic excitation via endocannabinoid release. J Neurosci 26:6643-6650.

Moos FC, Rossi K, Richard P (1997) Activation of N-methyl-D-aspartate receptors regulates basal electrical activity of oxytocin and vasopressin neurons in lactating rats. Neuroscience 77:993-1002.

Mukherjee AB, Loesch A (2002) Co-localisation of nitric oxide synthase and endothelin in the rat supraoptic nucleus. Histochem J 34:181-187.

Nakamura S, Naruse M, Naruse K, Shioda S, Nakai Y, Uemura H (1993) Colocalization of immunoreactive endothelin-1 and neurohypophysial hormones in the axons of the neural lobe of the rat pituitary. Endocrinology 132:530-533.

Nissen R, Hu B, Renaud LP (1995) Regulation of spontaneous phasic firing of rat supraoptic vasopressin neurones in vivo by glutamate receptors. J Physiol 484:415-424.

Oliet SH, Baimoukhametova DV, Piet R, Bains JS (2007) Retrograde regulation of GABA transmission by the tonic release of oxytocin and endocannabinoids governs postsynaptic firing. J Neurosci 27:1325-1333.

Pittman QJ, Mulligan SJ (2008) Dendritic vasopressin release: reducing the flow makes blood vessels grow. Endocrinology 149:4276-4278.

Regehr WG, Carey MR, Best AR (2009) Activity-dependent regulation of synapses by retrograde messengers. Neuron 63:154-170.

Ritz MF, Stuenkel EL, Dayanithi G, Jones R, Nordmann JJ (1992) Endothelin regulation of neuropeptide release from nerve endings of the posterior pituitary. Proc Natl Acad Sci U S A 89:8371-8375.

Rossi NF (1993) Effect of endothelin-3 on vasopressin release in vitro and water excretion in vivo in Long-Evans rats. J Physiol 461:501-511.

Rossi NF (1995) Cation channel mechanisms in ET-3-induced vasopressin secretion by rat hypothalamo-neurohypophysial explants. Am J Physiol 268:E467-E475.

Rossi NF (2004) Regulation of vasopressin secretion by ETA and ETB receptors in compartmentalized rat hypothalamo-neurohypophysial explants. Am J Physiol Endocrinol Metab 286:E535-E541.

Rossi NF, Chen H (2002) Modulation of ET(B) receptor-induced argininevasopressin secretion by $\mathrm{N}$-methyl-D-aspartate (NMDA) and gammaaminobutyric and (GABA)-dependent mechanisms in hypothalamoneurohypophysial explants. Clin Sci 103 [Suppl 48]:162S-166S.

Rossi NF, Chen H (2006) Aminopropionic acid receptors in paraventricular nucleus mediate pressor and vasopressin responses to endothelin-1 in subfornical organ. Exp Biol Med (Maywood) 231:1075-1080.

Rossi NF, O'Leary DS, Chen H (1997a) Mechanisms of centrally administered ET-1-induced increases in systemic arterial pressure and AVP secretion. Am J Physiol 272:E126-E132.

Rossi NF, O'Leary DS, Scislo TJ, Caspers ML, Chen H (1997b) Central endothelin 1 regulation of arterial pressure and arginine vasopressin secretion via the AV3V region. Kidney Int Suppl 61:S22-S26.

Rossi NF, Maliszewska-Scislo M, Chen H (2008) Central endothelin: effects on vasopressin and the arterial baroreflex in doxorubicin heart failure rats. Can J Physiol Pharmacol 86:343-352.

Sabatier N, Leng G (2006) Presynaptic actions of endocannabinoids mediate $\alpha$-MSH-induced inhibition of oxytocin cells. Am J Physiol Regul Integr Comp Physiol 290:R577-R584.

Samson WK, Skala KD, Alexander BD, Huang FL (1991) Hypothalamic en- dothelin: presence and effects related to fluid and electrolyte homeostasis. J Cardiovasc Pharmacol 17 [Suppl 7]:S346-S349.

Schinelli S, Zanassi P, Paolillo M, Wang H, Feliciello A, Gallo V (2001) Stimulation of endothelin $\mathrm{B}$ receptors in astrocytes induces cAMP response element-binding protein phosphorylation and c-fos expression via multiple mitogen-activated protein kinase signaling pathways. J Neurosci 21:8842-8853.

Shibuya I, Kabashima N, Ibrahim N, Setiadji SV, Ueta Y, Yamashita H (2000) Pre- and postsynaptic modulation of the electrical activity of rat supraoptic neurones. Exp Physiol 85 [Spec No]:145S-151S.

Shichiri M, Hirata Y, Kanno K, Ota K, Emori T, Marumo F (1989) Effect of endothelin-1 on release of arginine-vasopressin from perifused rat hypothalamus. Biochem Biophys ResCommun 163:1332-1337.

Stern JE, Armstrong WE (1995) Electrophysiological differences between oxytocin and vasopressin neurones recorded from female rats in vitro. J Physiol 488:701-708.

Tasker JG, Dudek FE (1991) Electrophysiological properties of neurones in the region of the paraventricular nucleus in slices of rat hypothalamus. J Physiol 434:271-293.

Ueta Y, Fujihara H, Serino R, Dayanithi G, Ozawa H, Matsuda K, Kawata M, Yamada J, Ueno S, Fukuda A, Murphy D (2005) Transgenic expression of enhanced green fluorescent protein enables direct visualization for physiological studies of vasopressin neurons and isolated nerve terminals of the rat. Endocrinology 146:406-413.

Venance L, Stella N, Glowinski J, Giaume C (1997) Mechanism involved in initiation and propagation of receptor-induced intercellular calcium signaling in cultured rat astrocytes. J Neurosci 17:1981-1992.

Venance L, Prémont J, Glowinski J, Giaume C (1998) Gap junctional communication and pharmacological heterogeneity in astrocytes cultured from the rat striatum. J Physiol 510:429-440.

Wall KM, Ferguson AV (1992) Endothelin acts at the subfornical organ to influence the activity of putative vasopressin and oxytocin-secreting neurons. Brain Res 586:111-116.

Walter L, Stella N (2003) Endothelin-1 increases 2-arachidonoyl glycerol (2-AG) production in astrocytes. Glia 44:85-90.

Walter L, Franklin A, Witting A, Moller T, Stella N (2002) Astrocytes in culture produce anandamide and other acylethanolamides. J Biol Chem 277:20869-20876.

Yamamoto S, Inenaga K, Kannan H, Eto S, Yamashita H (1993) The actions of endothelin on single cells in the anteroventral third ventricular region and supraoptic nucleus in rat hypothalamic slices. J Neuroendocrinol 5:427-434.

Yamamoto T, Uemura H (1998) Distribution of endothelin-B receptor-like immunoreactivity in rat brain, kidney, and pancreas. J Cardiovasc Pharmacol 31 [Suppl 1]:S207-S211.

Yanagisawa M, Kurihara H, Kimura S, Tomobe Y, Kobayashi M, Mitsui Y, Yazaki Y, Goto K, Masaki T (1988) A novel potent vasoconstrictor peptide produced by vascular endothelial cells. Nature 332:411-415.

Yoshizawa T, Shinmi O, Giaid A, Yanagisawa M, Gibson SJ, Kimura S, Uchiyama Y, Polak JM, Masaki T, Kanazawa I (1990) Endothelin: a novel peptide in the posterior pituitary system. Science 247:462-464.

Zimmermann M, Seifert V (1998) Endothelin and subarachnoid hemorrhage: an overview. Neurosurgery 43:863-875. 